\title{
BMJ Open Probiotics for the prevention of antibiotic-associated diarrhoea: a systematic review and meta-analysis
}

\author{
Clare Goodman (D) , ${ }^{1}$ Georgia Keating, ${ }^{2}$ Ekavi Georgousopoulou, ${ }^{1}$ \\ Charlotte Hespe (D) , ${ }^{1}$ Kate Levett (D) ${ }^{1}$
}

To cite: Goodman C, Keating G, Georgousopoulou E, et al. Probiotics for the prevention of antibiotic-associated diarrhoea: a systematic review and meta-analysis. BMJ Open 2021;11:e043054. doi:10.1136/ bmjopen-2020-043054

- Prepublication history and supplemental material for this paper is available online. To view these files, please visit the journal online (http://dx.doi. org/10.1136/bmjopen-2020043054).

Received 26 July 2020 Accepted 16 July 2021

Check for updates

(C) Author(s) (or their employer(s)) 2021. Re-use permitted under CC BY-NC. No commercial re-use. See rights and permissions. Published by BMJ.

${ }^{1}$ National School of Medicine, The University of Notre Dame Australia, Sydney, New South Wales, Australia

${ }^{2}$ Department of Pharmacy, Alice Springs Hospital, Alice Springs, Northern Territory, Australia

Correspondence to

Dr Clare Goodman;

kate.levett@nd.edu.au

\section{ABSTRACT}

Objective To evaluate existing evidence for the use of probiotics in preventing antibiotic-associated diarrhoea (AAD) in adults.

Design Systematic review and meta-analysis of randomised controlled trials (RCTs).

Data sources We performed a literature search of the electronic databases CINAHL Plus, EMBASE, MEDLINE (Ovid) and Web of Science from database inception to May 2021 as well as hand searching of trial registries and reference lists of related reviews.

Study selection Two reviewers identified whether RCTs met the following inclusion criteria: adult population to whom antibiotics were administered; a probiotic intervention; a placebo, alternative dose, alternative probiotic strain or no treatment control; and incidence of AAD as the outcome.

Data extraction and synthesis Two reviewers independently collected data and assessed risk of bias using preconstructed data extraction forms. We used a random effects model for all analyses. Subgroup analyses were performed to evaluate species-specific and dosespecific response.

Results Forty-two studies (11,305 participants) were included in this review. The pooled analysis suggests that coadministration of probiotics with antibiotics reduces the risk of $A A D$ in adults by $37 \%$ (risk ratio $(\mathrm{RR})=0.63(95 \% \mathrm{Cl} 0.54$ to $0.73), p<0.00001)$. The overall quality of the evidence using the Grading of Recommendations, Assessment, Development and Evaluations (GRADE) criteria was found to be moderate. In subgroup analyses, high dose compared with low dose of the same probiotic demonstrated a positive protective effect (RR 0.54 (95\% Cl 0.38 to 0.76 ), $\mathrm{p}<0.01)$, and only certain species, mainly of the lactobacillus and bifidobacteria genera, were found to be effective. Studies with a low baseline AAD risk did not show any difference in risk but studies with moderate or high baseline AAD risk demonstrated a significant risk reduction.

Conclusions Probiotics are effective for preventing AAD. Secondary analyses of higher dosages and certain species have shown increased effectiveness. Our results may not be applicable in clinical scenarios of lower baseline AAD risk.

\section{INTRODUCTION}

Antibiotics are one of the most prescribed medications worldwide. They disturb normal gastrointestinal microbiota ${ }^{1}$ and a common consequence is diarrhoea. ${ }^{2}$ This leads to

\section{Strengths and limitations of this study}

An updated literature search encapsulating 4 years of new data since a comparable meta-analysis was last published by Cochrane in 2017.

- We calculated and reported the number needed to be treated with probiotics to protect one person from antibiotic-associated diarrhoea (AAD), so that our data can be easily interpreted by patients and clinicians.

- This meta-analysis looked only at incidence of AAD, but clinical applicability may have been improved by collecting data on duration and severity of AAD as well as length of stay in hospital and quality of life measures.

- There was complexity in combining results due to substantial heterogeneity between study methodologies and outcome measures.

prolonged hospital admissions, ${ }^{3}$ increased morbidity and mortality, ${ }^{4}$ and greater costs to the health system. ${ }^{56}$ Antibiotic-associated diarrhoea (AAD) has been reported in 5\%-35\% of patients receiving antibiotics, varying with the type of antibiotics, the general health of the patient and their exposure to pathogens. ${ }^{7}$

Probiotics are live micro-organisms that, when administered in adequate amounts, confer a health benefit on the host. ${ }^{8}$ They are believed to improve the microbial balance of the host and reduce colonisation by pathogenic bacteria. They can be delivered orally, are thought to adhere to target gastrointestinal epithelium and are stable in acid and bile. ${ }^{9}$ Probiotics are increasingly available in capsules, powders and fermented milk drinks and are promoted in health food shops and supermarkets, and in the media, for a multitude of purposes.

Several mechanisms are proposed to contribute to the protective effect of probiotics against AAD. Antibiotics are known to disrupt the complex balance of gastrointestinal microbiota, allowing colonisation by pathogenic organisms such as Clostridium 
difficile. Probiotics are believed to temporarily colonise the gut, producing bactericidal acids and peptides, and competing for nutrients and epithelial adhesion. Several species of the Lactobacillus genus are acid producing, lower environmental $\mathrm{pH}$, and secrete exotoxins that inhibit pathogenic bacterial growth and inhibit binding of enterotoxins to gut epithelium. ${ }^{10-13}$ Probiotics, particularly species in the Lactobacillus and Saccharomyces genera, are also reported to upregulate both the innate and adaptive immune systems through multiple mechanisms. ${ }^{14-17}$

It is suggested that probiotics are the panacea to AAD. This would be a very attractive solution to an expensive problem with significant morbidity. It is estimated that the increase in length of hospital stay due to $\mathrm{AAD}$ is 3.6-21.3 days. ${ }^{18} 19$ One of the most expensive probiotics in Australia costs less than nine dollars daily (VSL\#3 probiotic formulation, $\$ A 8.60$ per day, April 2021). This is negligible compared with the cost of 1 day of Australian hospital inpatient care, which according to 2017 data, cost on average $\$$ A2128. ${ }^{20}$

Our hypothesis has been extensively investigated. In a Cochrane review ${ }^{21}$ authors found moderate quality evidence for a large protective effect of probiotics against C. difficile-associated diarrhoea (CDAD) (RR 0.40, 95\% CI 0.30 to 0.52$)$. Although $C$. difficile is the most common infectious organism isolated, in most cases of $\mathrm{AAD}$ no causative agent is found. Faecal analysis indicates incidence of C. difficile in AAD to be $20 \%,{ }^{22}$ or less. ${ }^{23}$ Furthermore, while probiotics significantly reduce incidence of CDAD they do not appear to reduce C. difficile infection. ${ }^{21}$ Goldenberg and colleagues suggest that the role of probiotics may be more in alleviating the symptoms of infection rather than preventing colonisation itself. ${ }^{21}$ For this reason, we examined the protective effect of probiotics on the occurrence of $\mathrm{AAD}$ without any specific causative organism.

The primary objective of this systematic review and meta-analysis was to evaluate existing evidence for the protective effect of probiotics against $\mathrm{AAD}$ in adults. Secondary objectives were to examine dose-response and species-specific response in preventing AAD.

\section{METHODS}

\section{Eligibility criteria}

Randomised controlled trials (RCTs) comparing probiotic use (any strain, dose or formulation) to placebo, alternative dose, alternative probiotic strain or no treatment, for the prevention of diarrhoea in adults receiving antibiotic therapy, were eligible for inclusion in this review. Studies of adults, receiving any antibiotic therapy for a course of any length, or for any reason, were included. Studies of paediatric populations were excluded. The primary outcome measure was incidence of $\mathrm{AAD}$, as defined by authors, during the antibiotic treatment or follow-up phases. Studies were excluded if they examined probiotics only for treatment, rather than prevention, of AAD.
We limited included studies to those written in English as our group did not speak any other languages.

\section{Information sources and search strategy}

A comprehensive electronic title search (online supplemental file 1) was performed of CINAHL Plus, EMBASE, MEDLINE (Ovid), Web of Science and Google Scholar from database inception to May 2021. The search was broad to include as many individual probiotic species as possible and all clinical indications or outcomes (full search terms in Appendix A). Grey literature and clinical trial registers including ClinicalTrials.gov and the Australia New Zealand Clinical Trials Registry (ANZCTR) were searched, as well as hand searching of reference lists of relevant systematic reviews and included studies. The search was limited to RCTs in an adult population.

\section{Study selection}

Two of three of the authors (CG, GK and KL) independently assessed each study for inclusion in the review. Discrepancies were resolved through discussion.

\section{Data collection process and data items}

Data were extracted from each article by two of three of the authors (CG, GK, KL), using a standardised data extraction form following the Preferred Reporting Items for Systematic Reviews and Meta-Analyses (PRISMA) guidelines. ${ }^{24}$ This was housed within Covidence online software (Covidence systematic review software, Veritas Health Innovation, Melbourne, Australia; available at www.covidence.org). Data items collected included the number of patients allocated to each group, the probiotic species, formulation, dose and regime, whether a placebo or 'nothing' control was used, and outcome data on incidence of AAD.

\section{Assessment of risk of bias in individual studies and overall quality of the evidence}

The risk of bias was assessed using the Cochrane Risk of Bias $^{25}$ tool within the Covidence online software. The domains assessed were sequence generation, allocation concealment, blinding of participants and personnel, blinding of outcome assessors, incomplete outcome data, selective outcome reporting and other sources of bias (eg, differences in baseline characteristics or funding of trials by pharmaceutical companies). Assessment was conducted by two of three authors (CG, GK, KL) and discrepancies resolved by consensus. The overall quality of the evidence was rated using the Grading of Recommendations, Assessment, Development and Evaluations (GRADE) approach ${ }^{26}$ independently by two authors (CG, $\mathrm{KL}$ ) and consensus reached through discussion.

\section{Statistical analysis and measures of treatment effect}

For data analysis we used the RevMan V.5.4.1 statistical software (Review Manager (RevMan) (Computer program), V.5.4, The Cochrane Collaboration, 2020). Using a random-effects model, dichotomous data were reported as a risk ratio (RR) with corresponding $95 \%$ CIs. The 


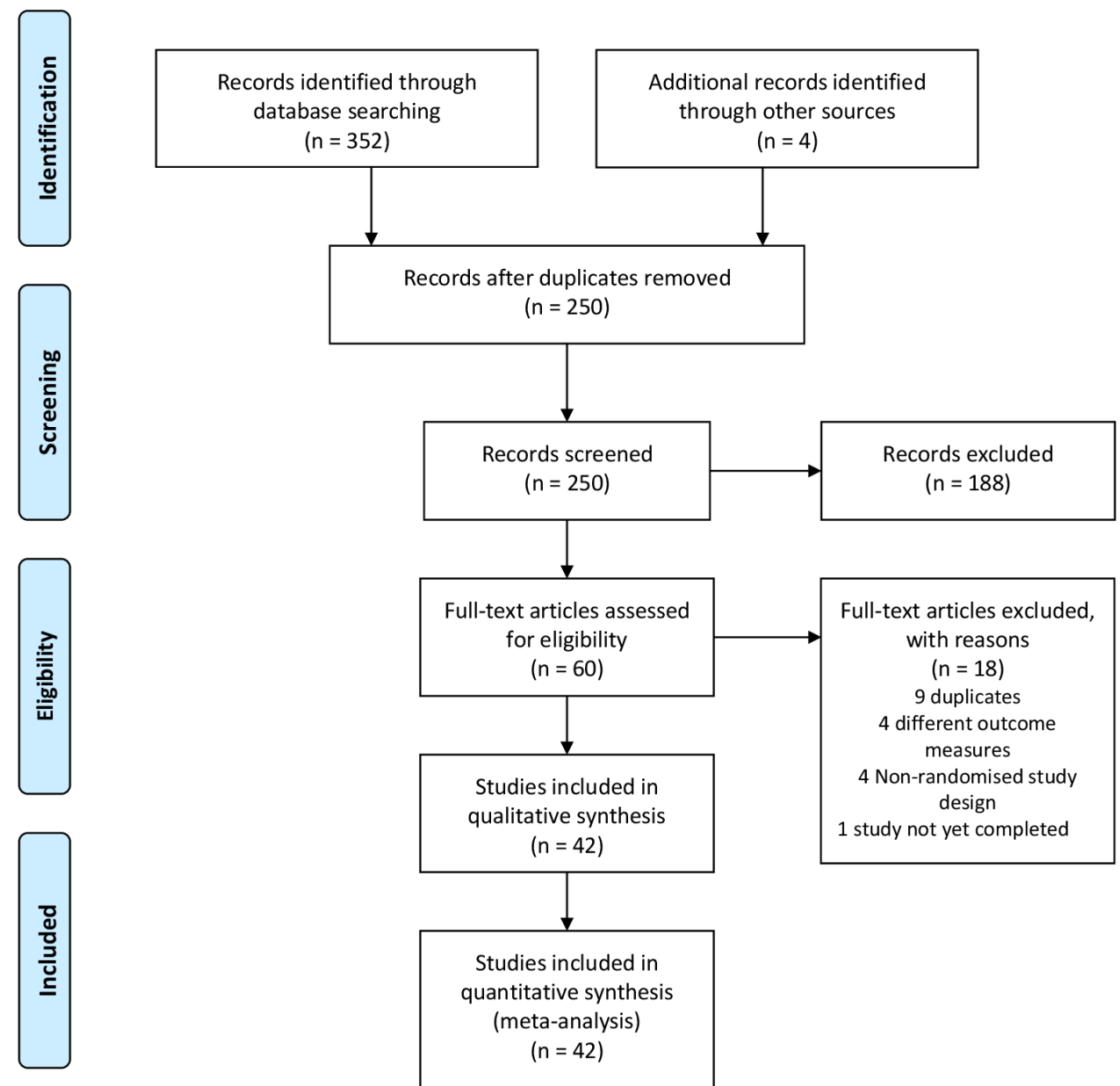

Figure 1 Preferred Reporting Items for Systematic Reviews and Meta-Analyses (PRISMA) flow diagram depicting the phases of this systematic review. A total of 352 articles were identified in the initial search, 250 remained after removal of duplicates, of which 60 were eligible for full-text review and 42 of those articles were eligible for inclusion in the study. ${ }^{24}$

number needed to treat (NNT) was also calculated for the complete case analysis. The $\mathrm{I}^{2}$ statistic was reported for statistical heterogeneity, although clinical and methodological heterogeneity would not have been reflected within this test. Our a priori clinical heterogeneity variables included: probiotic dose, probiotic species and risk of bias. We also conducted post hoc subgroup analyses on baseline risk for our primary outcome, incidence of $\mathrm{AAD}$, and concurrent use of probiotics with $H$. pylori eradication. Sensitivity analyses were performed where deemed necessary.

\section{Patient and public involvement}

There was no patient or public involvement in this study.

\section{RESULTS}

\section{Study selection and characteristics}

A total of 356 articles were identified in the initial search, of which 60 were eligible for full-text review, and 42 of those articles (11 305 participants) were eligible for inclusion in the study. Five of these were published after the Cochrane review mentioned previously. ${ }^{21}$ Figure 1 summarises the PRISMA flow of studies. The characteristics of each included study are presented in table 1.
All included studies were RCTs, conducted in adult populations. The overall age range was from 15 to 85 years. Interventions were comparable, in terms of all being probiotics, however, there was variation in the dose and species of probiotic used as well as the probiotic formulation ie, tablets, powder, yoghurt or fermented milk drink. We investigated these by subgroup analysis. All included studies reported on the outcome of interest; incidence of AAD. However, this was measured differently between studies and was not the primary research question of the trial in all cases.

\section{Risk of bias within studies}

The risk of bias summary is displayed in figure 2. Six of the 42 studies were rated as having a low risk of bias, while 36 were rated as having a high or unclear risk of bias. On sensitivity analysis, the low risk of bias studies demonstrated no protective effect of probiotics ( $\mathrm{RR}=0.78$ (95\% CI 0.57 to $1.07), \mathrm{p}=0.13$ ) as opposed to the high or unknown risk of bias studies ( $R R=0.59$ (95\% CI 0.50 to 0.70$), p<0.00001)$.

\section{Results of individual studies and synthesis of results}

Of the 42 studies included (table 1), 33 were placebocontrolled and eight provided 'no treatment' as the 


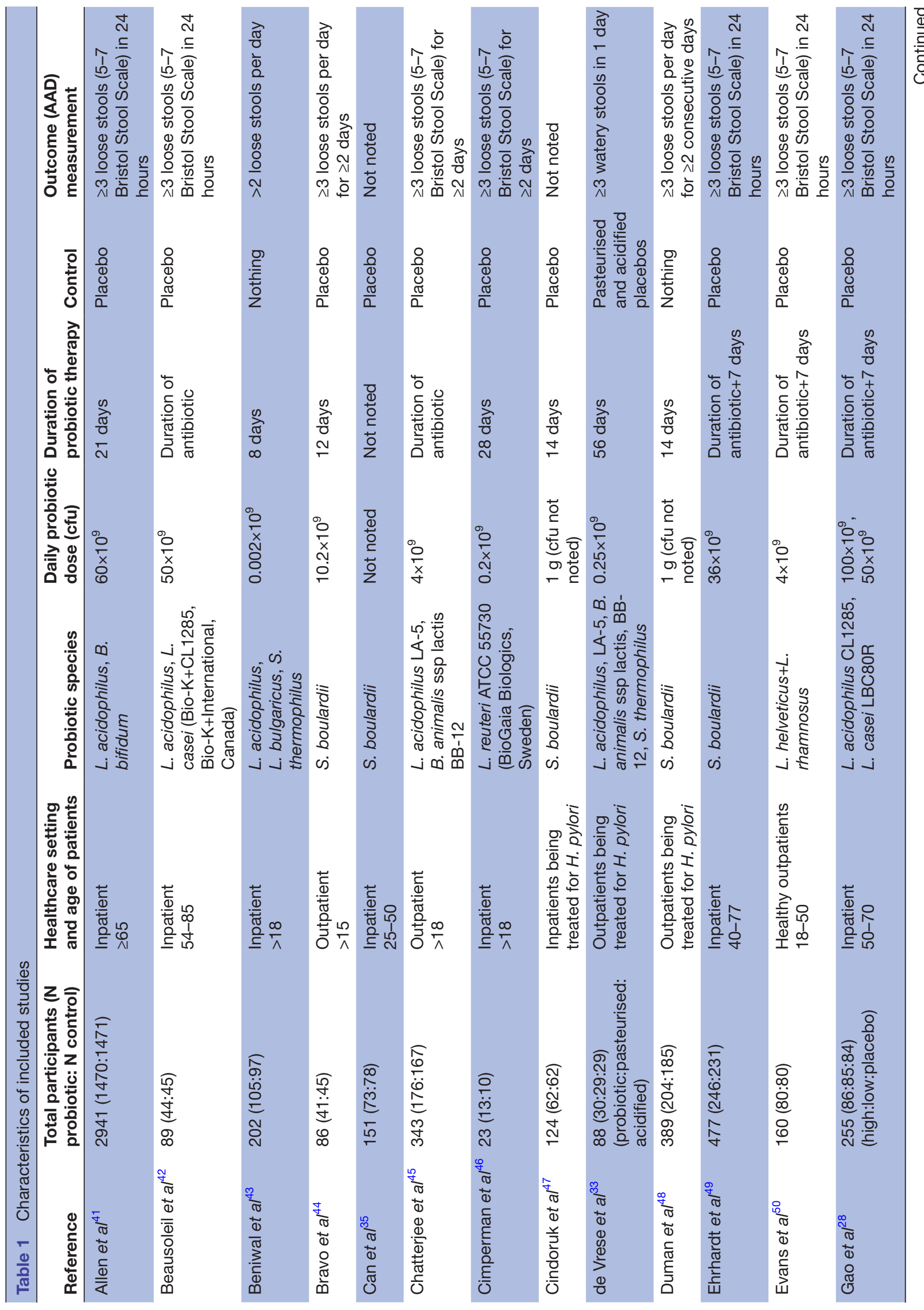




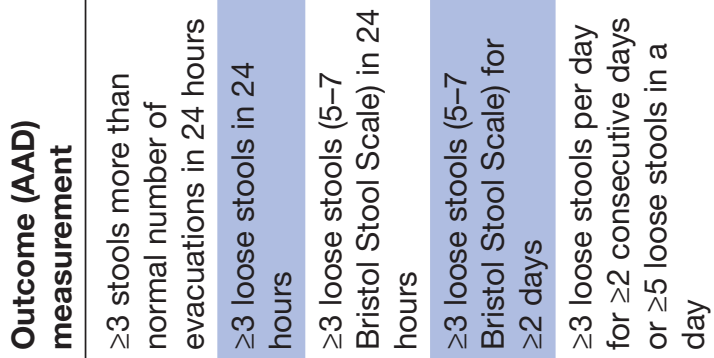

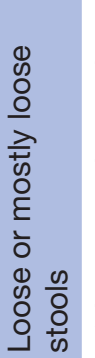

항
$\frac{1}{0}$
$\frac{0}{2}$
$\frac{10}{0}$
$\frac{0}{4}$

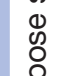

$\frac{1}{\infty}$

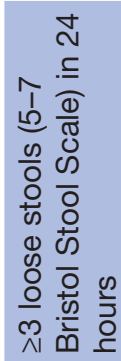

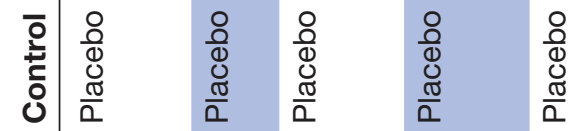

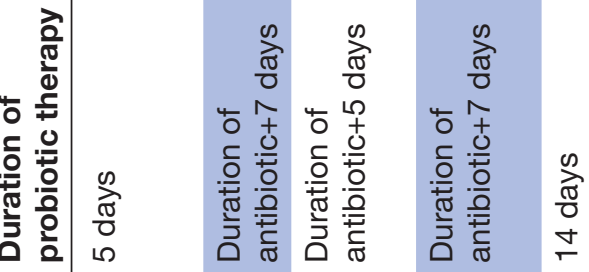

은

응

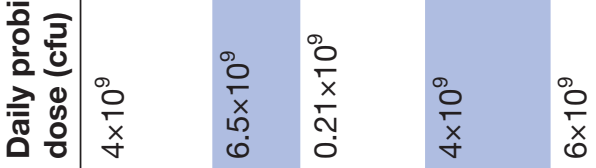

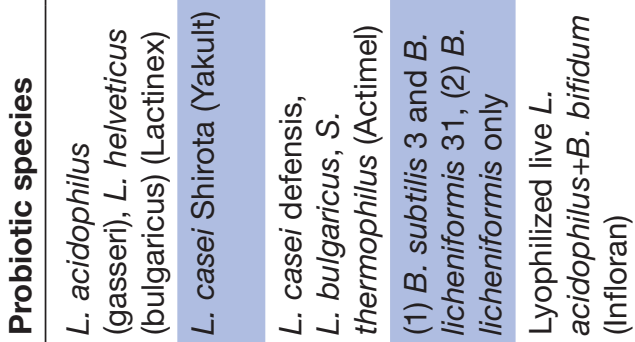

突

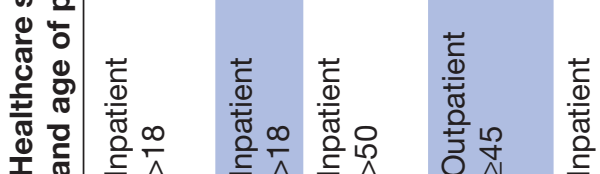

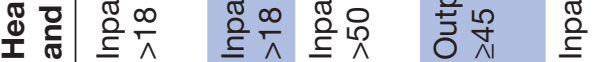

z

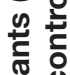

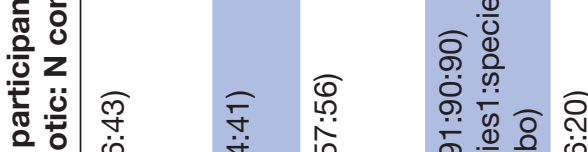

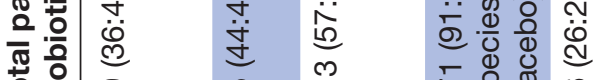

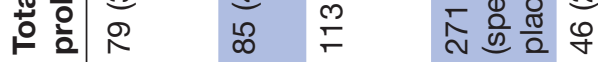

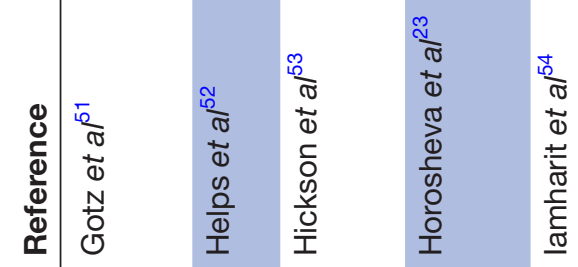

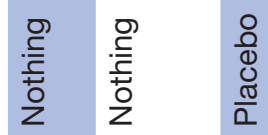

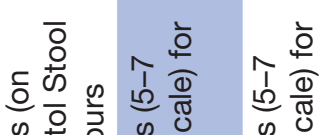

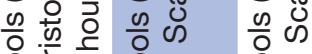

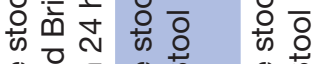

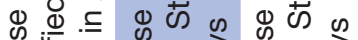

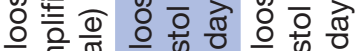

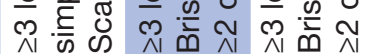

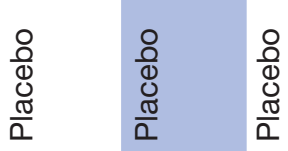

응으

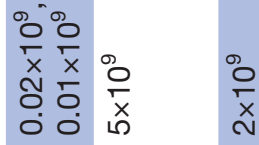

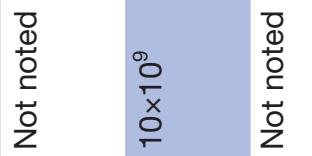
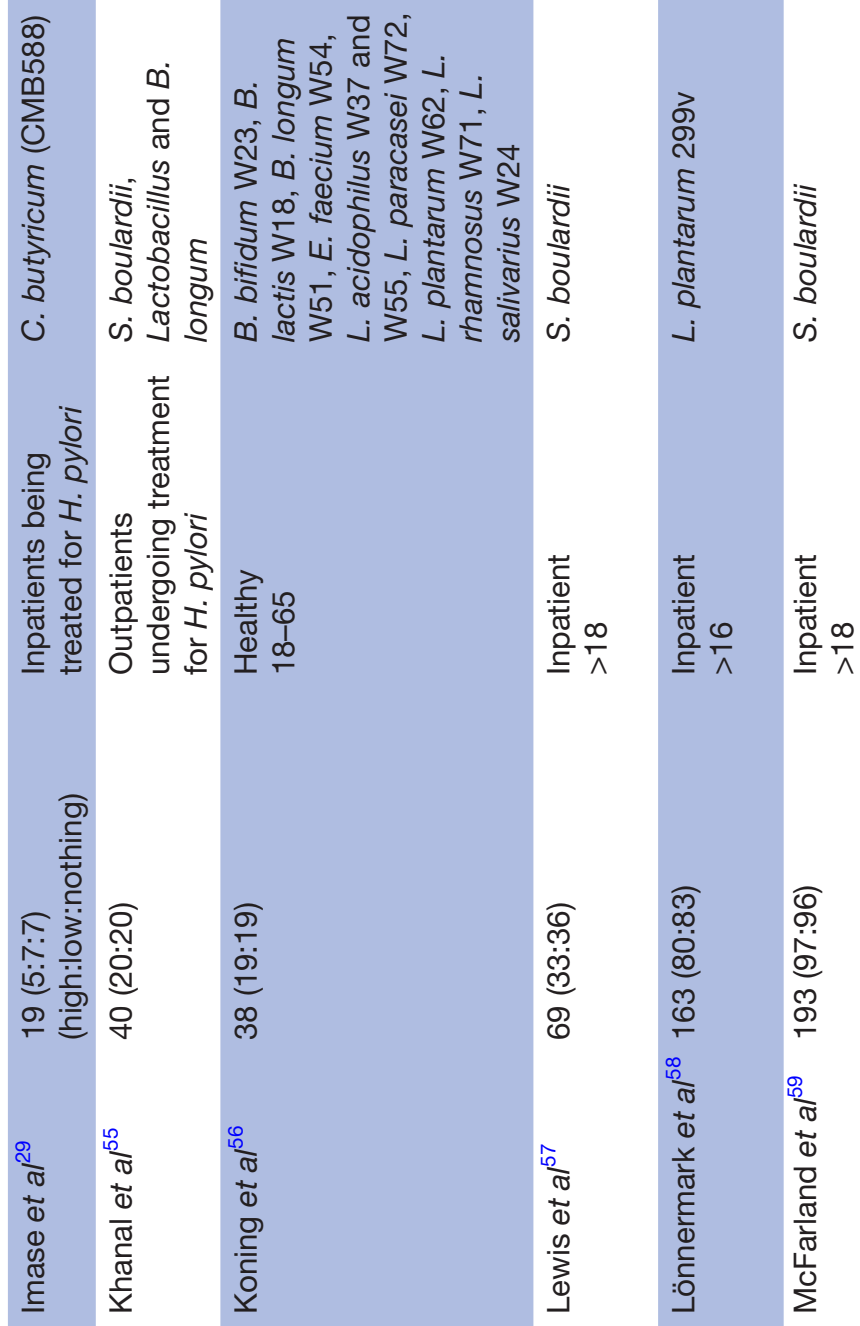

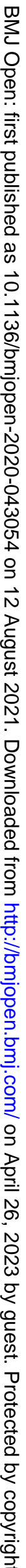




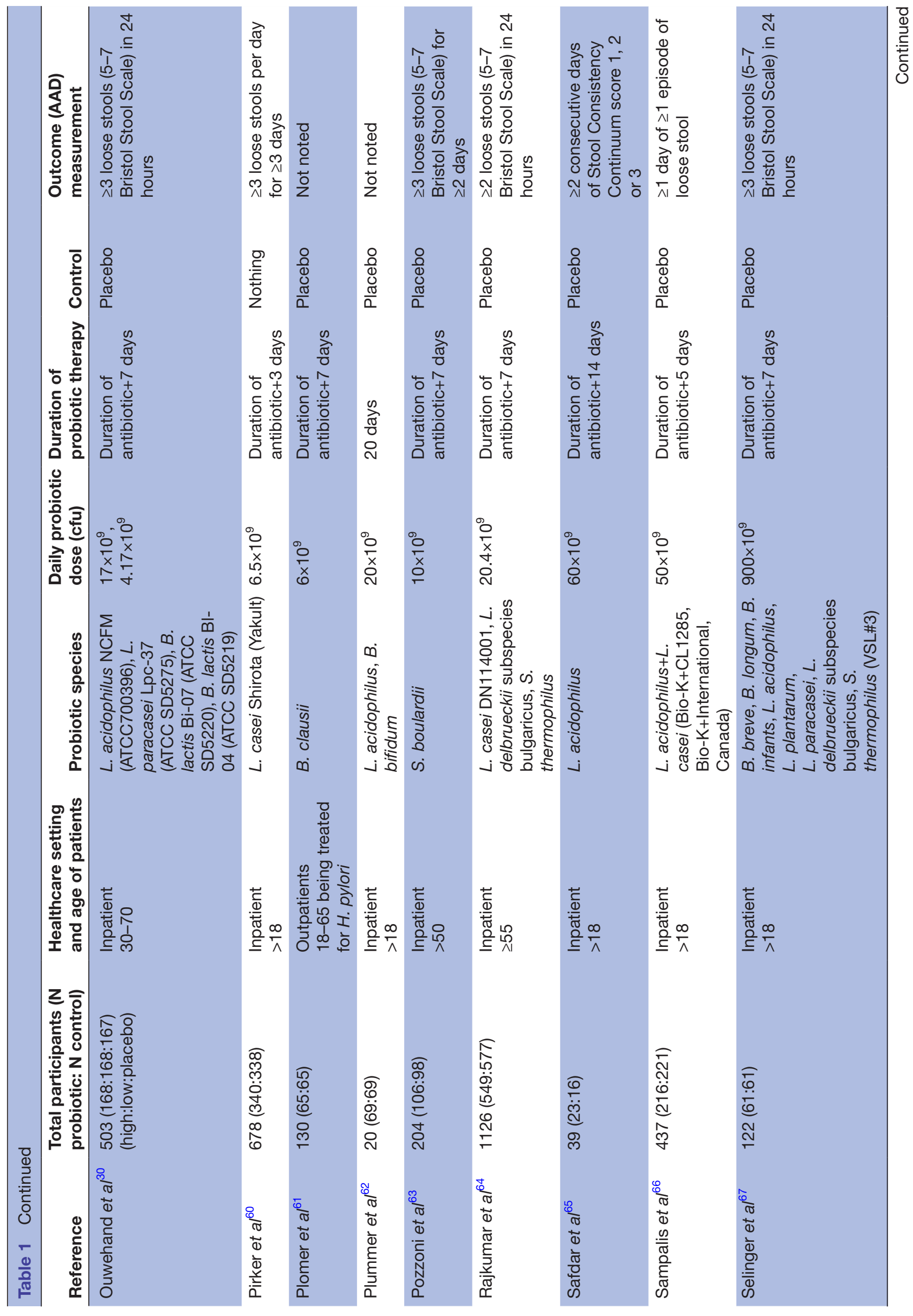

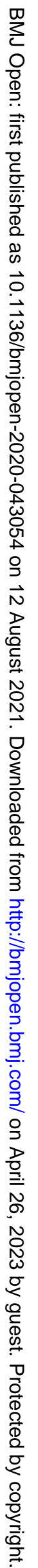




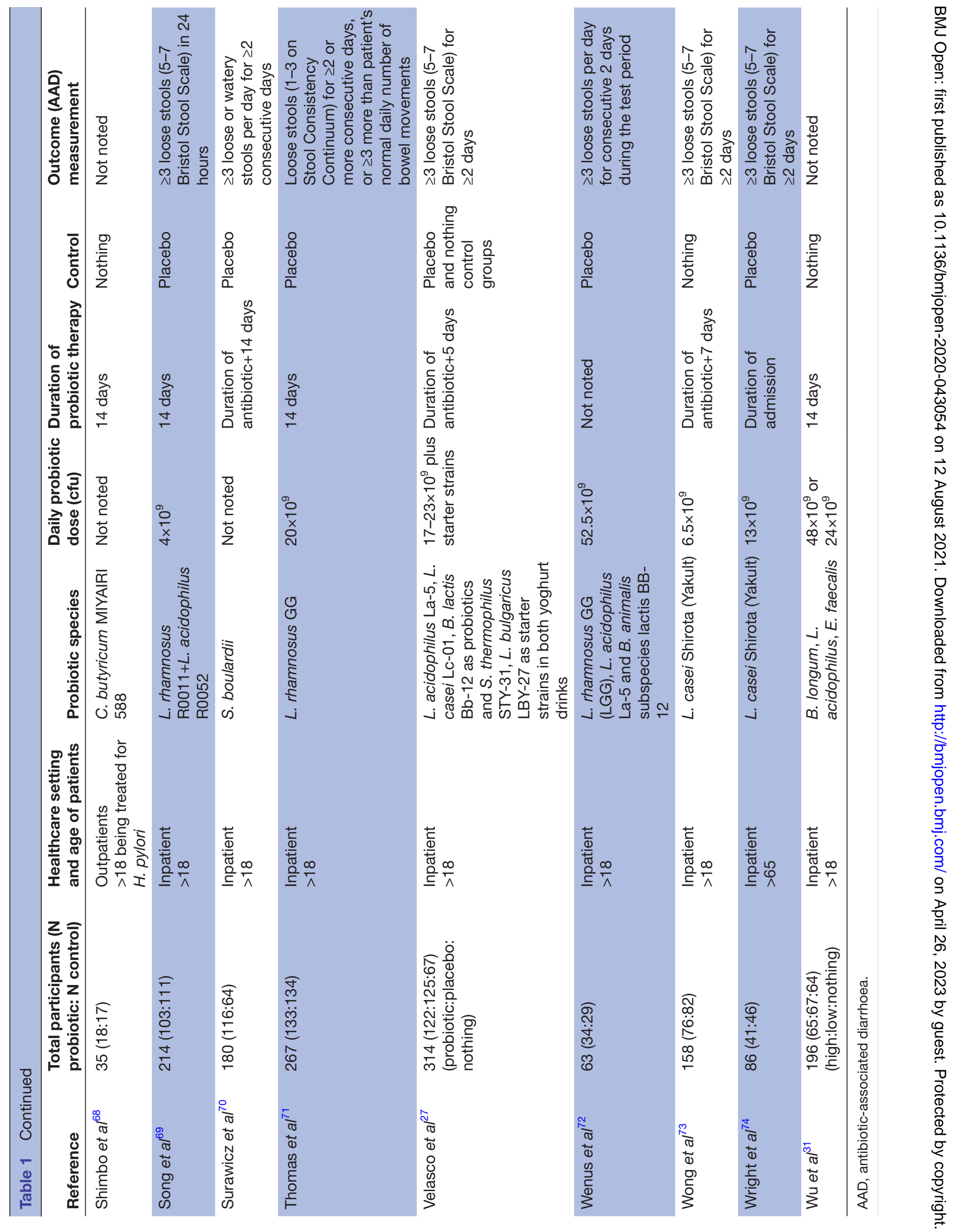




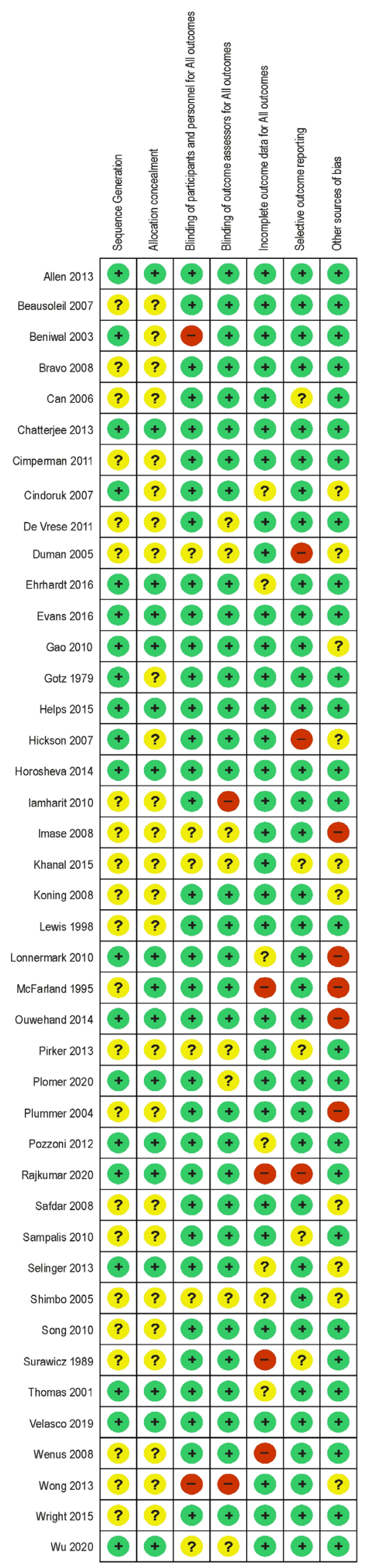

Figure 2 Risk of bias summary: review authors' judgements about each risk of bias item for each included study. comparison. One study compared its treatment group to both a placebo group and a no treatment control. ${ }^{27}$ Four trials compared two probiotic arms of differing doses with a control group. ${ }^{28-31}$ Where there were two treatment groups (eg, high dose and low dose) and one control group, the control group was split so that half served as comparator for each arm, in accordance with the Cochrane Systematic Review Guidelines. ${ }^{32}$ Similarly in one study ${ }^{33}$ where a probiotic group was compared with a placebo and 'no treatment' control, the probiotic group was split. In one study ${ }^{27}$ the placebo milk containeda higher concentration of starter strains than the probiotic milk. We combined the groups to make it an overall treatment group, which the authors had done themselves in the 'both' group, compared with a 'no treatment' group. Only one study was found to compare two strains of the same probiotic species; however, it was excluded as it was not randomised. ${ }^{34}$

The overall pooled results of the complete case analysis of 42 studies (reporting on 11305 participants) (figure 3), comparing probiotics with any control, favoured probiotics demonstrating a statistically significant reduction in the incidence of $\mathrm{AAD}$. The pooled RR of 0.63 ( $R R=0.63(95 \%$ CI 0.54 to 0.73$), \mathrm{p}<0.00001)$ indicates that those who took probiotics were over one-third less likely to develop AAD. These data suggest that the NNT, to prevent one case of AAD would be 20 patients. Statistically significant heterogeneity was detected for this comparison $\left(p<0.00001 ; I^{2}=60 \%\right)$. We used a random effects model for this analysis based on the heterogeneity of the study methodologies.

\section{Subgroup and heterogeneity analysis}

When subgroup analyses were performed, where probiotics were compared with placebo $(\mathrm{RR}=0.69 \quad(95 \%$ CI 0.60 to 0.80$), \mathrm{p}<0.00001)$, and where probiotics were compared with no treatment $(\mathrm{RR}=0.35(95 \%$ CI 0.27 to $0.47), \mathrm{p}<0.00001)$, a significant reduction in relative risk of diarrhoea was noted (Forest plots available in online supplemental file 1). The difference in effect size may be explained as placebo effect.

Across all of the subgroup analyses, the $\mathrm{I}^{2}$ statistic ranged from $0 \%$ to $78 \%$. There was also substantial clinical and methodological heterogeneity, therefore we used a random effects model for all analyses. There was substantial variation in the AAD definition employed in the included studies (table 1). Although 13 studies defined AAD as $\geq 3$ loose stools ( $5-7$ Bristol Stool Scale) in 24 hours, 12 defined AAD as $\geq 3$ loose stools (5-7 Bristol Stool Scale) in 2 days or more, 11 studies used various other definitions of $\mathrm{AAD}$ and 5 studies made no mention of their definition.

\section{Subgroup analysis: probiotic dose}

Four studies directly compared high dose and low dose of the same probiotic. ${ }^{28-31}$ The higher dose group demonstrated a significant reduction in the relative risk of AAD 
Probiotic

Control

Risk Ratio

Risk Ratio

Study or Subgroup Events Total Events Total Weight M-H, Random, 95\% CI 1.1.1 Study end-point

Allen 2013

Beausoleil 2007

Beniwal 2003

Bravo 2008

Can 2006

Chatterjee 2013

Cimperman 2011

Cindoruk 2007

DeVrese 2011

Duman 2005

Ehrhardt 2016

Evans 2016

Gao 2010

Gotz 1979

Helps 2015

Hickson 2007

Horosheva 2014

lamharit 2010

Imase 2008

Khanal 2015

Koning 2008

Lewis 1998

Lnnermark 2010

McFarland 1995

Ouwehand 2014

Pirker 2013

Plomer 2020

Plummer 2004

Pozzoni 2012

Rajkumar 2020

Safdar 2008

Sampalis 2010

Selinger 2013

Shimbo 2005

Song 2010

Surawicz 1989

Thomas 2001

Velasco 2019

Wenus 2008

Wong 2014

Wright 2015

Wu 2020

Subtotal $(95 \% \mathrm{Cl})$

Total events

Heterogeneity: $\mathrm{Tau}^{2}=0.12 ; \mathrm{Chi}^{2}=101.25, \mathrm{df}=41(\mathrm{P}<0.00001) ; \mathrm{I}^{2}=60 \%$

Test for overall effect: $Z=5.92(P<0.00001)$

Total $(95 \% \mathrm{Cl})$

Total events

5985

822

1591470

$\begin{array}{lrrr}7 & 44 & 153 & 1471\end{array}$

$13 \quad 105$

$4 \quad 41$

173

$19 \quad 176$

113

962

430

204

246

80

171

36

44

57

181

26

12

20

9 19

33

7
7

97

336

340

65

69

106

$06 \quad 549$

$4 \quad 23$

216

61

18

103

$11 \quad 116$

$39 \quad 133$

$\begin{array}{ll}50 & 247\end{array}$

234

1376

541

$7 \quad 132$

5985 $\begin{array}{lll}153 & 1471 \quad 4.8 \%\end{array}$

$45 \quad 2.2 \%$

\begin{tabular}{l}
$47-2.8 \%$ \\
\hline
\end{tabular}

$5 \quad 45 \quad 1.2 \%$

\begin{tabular}{l}
$78-0.5 \%$ \\
\hline
\end{tabular}

$\begin{array}{lll}26 & 167 & 3.1 \%\end{array}$

$\begin{array}{lll}5 & 10 & 0.5 \%\end{array}$

$19 \quad 62 \quad 2.5 \%$

$\begin{array}{lll}5 & 58 & 1.2 \%\end{array}$

$\begin{array}{lll}28 & 185 & 2.9 \%\end{array}$

$\begin{array}{lll}19 & 231 & 3.0 \%\end{array}$

$29 \quad 80 \quad 3.5 \%$

$34 \quad 84 \quad 4.0 \%$

$9 \quad 43 \quad 1.2 \%$

$14 \quad 41 \quad 3.0 \%$

$19 \quad 56 \quad 2.2 \%$

$23 \quad 90 \quad 3.0 \%$

$\begin{array}{lll}0 & 20 & 0.3 \%\end{array}$

$0.5 \%$

$0.5 \%$

$3.3 \%$

$1.6 \%$

$1.4 \%$

$2.0 \%$

$4.1 \%$

$3.3 \%$

$4.0 \%$

$2.8 \%$

$2.6 \%$

$4.6 \%$

$1.5 \%$

$4.3 \%$

$0.3 \%$

$0.4 \%$

$2.3 \%$

$2.4 \%$

$4.0 \%$

$3.3 \%$

$0.9 \%$

$3.2 \%$

$1.2 \%$

$3.4 \%$

$5320 \quad 100.0 \%$
$1.04[0.84,1.28]$

$0.45[0.20,0.98]$

$0.52[0.28,0.97]$

$0.88[0.25,3.05]$

$0.15[0.02,1.21]$

$0.69[0.40,1.20]$

$0.15[0.02,1.12]$

$0.47[0.23,0.96]$

$1.55[0.45,5.34]$

$0.45[0.25,0.83]$

$1.04[0.57,1.88]$

$0.72[0.45,1.16]$

$0.53[0.36,0.79]$

$0.40[0.12,1.36]$

$1.06[0.60,1.90]$

$0.36[0.17,0.79]$

$0.35[0.19,0.62]$

$5.44[0.30,99.72]$

$0.19[0.02,1.53]$

$0.20[0.03,1.56]$

$0.59[0.35,0.98]$

$1.53[0.54,4.35]$

$1.25[0.40,3.92]$

$0.49[0.21,1.17]$

$0.65[0.46,0.94]$

$0.27[0.16,0.45]$

$0.61[0.41,0.89]$

$1.00[0.53,1.88]$

$0.75[0.38,1.48]$

$1.08[0.85,1.38]$

$0.46[0.16,1.38]$

$0.69[0.50,0.94]$

$0.07[0.00,1.14]$

$0.47[0.05,4.74]$

$0.61[0.28,1.31]$

$0.43[0.21,0.90]$

$0.98[0.68,1.42]$

$0.97[0.57,1.64]$

$0.21[0.05,0.93]$

$0.32[0.19,0.54]$

$1.40[0.40,4.87]$

$0.44[0.26,0.72]$

$0.63[0.54,0.73]$

M-H, Random, 95\% Cl

Heterogeneity: $\mathrm{Tau}^{2}=0.12 ; \mathrm{Chi}^{2}=101.25, \mathrm{df}=41(\mathrm{P}<0.00001) ; \mathrm{I}^{2}=60 \%$

Test for overall effect: $Z=5.92(P<0.00001)$

Test for subgroup differences: Not applicable

$5320 \quad 100.0 \% \quad 0.63[0.54,0.73]$

0.0

010.1

Favours [experimental] Favours [control]

Figure 3 Forest plot of comparison. 1 probiotic versus any control, outcome: 1.1 incidence antibiotic-associated diarrhoea: complete case.

(RR 0.54 (95\% CI 0.38 to 0.76 ), $\mathrm{p}=0.0004$ ) (Forest plot available in online supplemental file 1).

\section{Subgroup analysis: probiotic species}

Most studies used probiotic formulations containing more than one probiotic species, so a subgroup analysis was performed on all individual species mentioned in included studies (table 2). Where only one study existed that used a particular strain, we analysed that study's outcome data alone. The following probiotic strains demonstrated significant reduction in AAD when compared with a control: L. acidophilus, $L$. bulgaricus, L. casei, L. paracasei, L. rhamnosus, Lactobacillus spp, S. boulardii, B. animalis ssp Lactis, B. longum, B. licheniformis, B. subtilis and Bacillus clausii. However, L. helveticus, L. plantarum, L. reuteri, B. bifidum, S. thermophilus and $C$. butyricum provided no improvement in AAD compared with control.

\section{Subgroup analysis: concurrent $\boldsymbol{H}$. pylori treatment}

In the seven RCTs investigating adjunct probiotic use with antibiotics for $H$. pylori treatment we found a reduction in 
Table 2 Subgroup analyses by species or genus (Forest plots for all subgroup analyses available in online supplemental file 1)

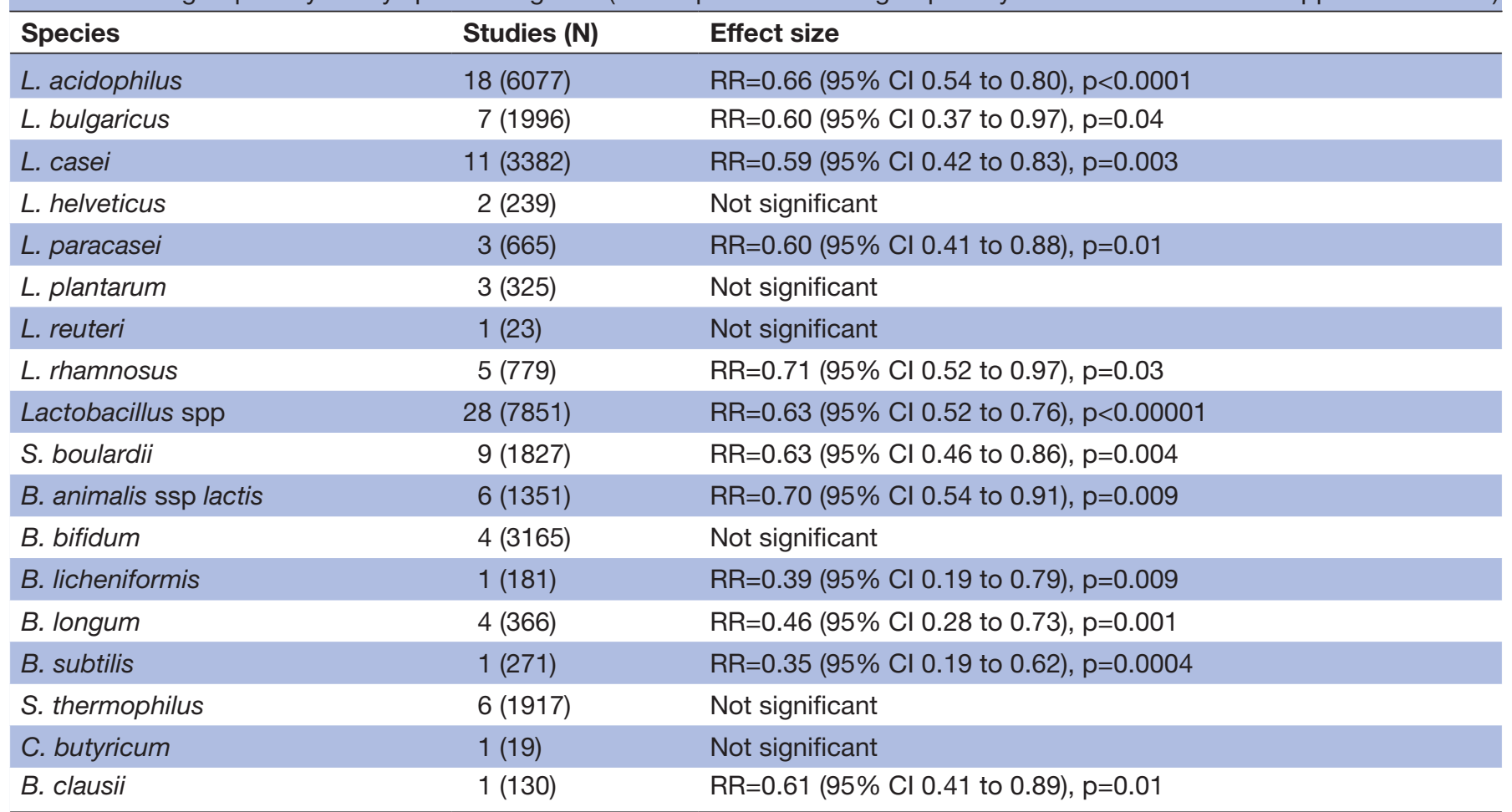

$\mathrm{RR}$, risk ratio.

diarrhoeal side effects of $45 \%(\mathrm{RR}=0.55$ (95\% CI 0.41 to $0.73), \mathrm{p}<0.0001$ ) (Forest plot available in online supplemental file 1).

\section{Sensitivity analysis: baseline risk of AAD}

In a post hoc analysis we divided our included studies into low (0\%-10\%; seven studies), moderate (11\%-30\%; 21 studies) and high (>31\%; 14 studies) baseline risk of AAD. The pooled studies with a low baseline risk of AAD did not show any difference in risk, but trials enrolling participants with a moderate or high baseline risk for developing AAD demonstrated 39\% ( $\mathrm{RR}=0.61 \quad(95 \%$ CI

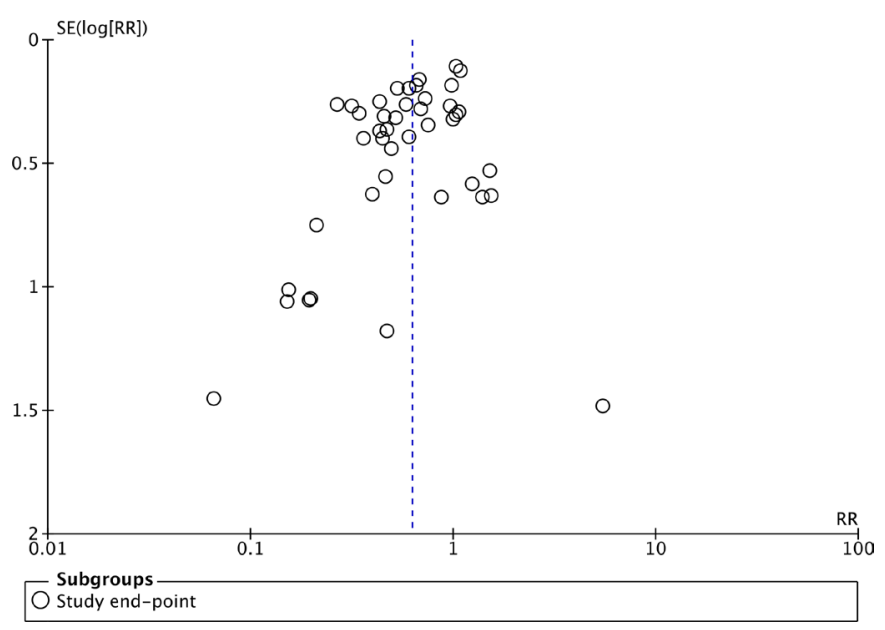

Figure 4 Funnel plot of comparison: 1 probiotic versus any control, outcome: 1.1 incidence antibiotic-associated diarrhoea: complete case. $\mathrm{RR}$, risk ratio.
0.48 to 0.78$), \mathrm{p}<0.0001)$ and $45 \%(\mathrm{RR}=0.55$ (95\% CI 0.46 to 0.66 ), $\mathrm{p}<0.00001$ ) risk reduction, respectively (Forest plots available in online supplemental file 1).

\section{Sensitivity analysis: high/unknown risk of bias}

To examine for robustness we pooled data from the studies which we assessed as low risk of bias in all domains, and separately pooled the studies which scored high or unknown risk of bias in any domain. In our sensitivity analysis with the high and unknown risk of bias studies removed, the protective effect of probiotics against AAD was no longer statistically significant $(\mathrm{RR}=0.78$ (95\% CI 0.57 to 1.07$), p=0.13$ ). However, with only the high risk of bias studies removed from the complete data set, a similar pooled protective effect of probiotics was found ( $R R=0.65$ (95\% CI 0.54 to 0.78$), \mathrm{p}<0.00001$ ) (Forest plots available in online supplemental file 1).

\section{Adverse events}

Of the 42 included studies, 32 reported on adverse events. No serious adverse events were reported in any of the included studies. One study reported four $(2.0 \%)$ non-serious adverse events in the probiotic group compared with none in the control group, ${ }^{35}$ and another commented that their probiotic milk was less well tolerated than their placebo milk. ${ }^{27}$

\section{Small study effects}

On inspection, the funnel plot of the complete case analysis (figure 4) is symmetrical, which suggests little evidence of publication bias. 


\section{Overall quality of evidence}

Using the GRADE approach ${ }^{26}$ we rated the overall quality of the evidence as moderate. Although all included studies were RCTs, many demonstrated design limitations, mainly reflecting the reporting of sequence generation and allocation concealment in older studies, which suggests some risk of bias. This was balanced, however, by a good magnitude of effect and dose-response gradient, increasing the certainty of this body of evidence.

\section{DISCUSSION}

\section{Summary of evidence}

The principal finding of this review is that probiotics significantly reduce the risk of AAD in adults, with an NNT of 20 patients. These results were robust in subgroup analyses, with high doses more effective than lower doses, and some species more effective than others. As is the nature of systematic reviews, we found significant heterogeneity in study designs and population, severity of illness of the study group, antibiotics administered, as well as probiotic species and strains used, dose, timing and duration of probiotic administration. It may be important to note that our subgroup analysis of low baseline risk studies failed to find a statistically significant effect of probiotics. Therefore our overall effect estimate may not be directly applicable to clinical scenarios with inherent lower baseline risk of AAD. Using the GRADE criteria, ${ }^{26}$ the quality of the evidence included in our meta-analysis was moderate and therefore it would be appropriate to base future clinical practice on our results.

Our results show evidence of a placebo effect, with a reduction in risk of $\mathrm{AAD}$ of $31 \%$ when probiotics were compared with placebo, but $65 \%$ when probiotics were compared with no treatment. Placebo effect is not well understood but this could be attributed to expectations of symptom change with neurobiological underpinnings and actual effects on the brain and body. ${ }^{36}$ This effect could be investigated further in well-designed, threearmed, RCTs.

Secondary objectives included subgroup analyses of dose-response and species-specific response. In studies where dosages of the same species were compared, ${ }^{28-31}$ higher doses showed a significantly greater benefit $(\mathrm{RR}=0.54)$. It is difficult to interpret the dosage effect as the four studies that compared different doses of the same probiotic species made comparisons of differing magnitudes. Probiotic course duration was reported in most studies (40 out of 42), ranging from 5 to 56 days. Most commonly, probiotics were administered for the duration of antibiotic therapy plus a further 7 days, or a total of 14 days. It would be biologically plausible to suggest that probiotic use should be continued for some period after the cessation of antibiotics. This is another question worth investigating in future trials.

Many studies used blends of probiotic species and strains, which made it problematic to establish independent associations. In our subgroup analyses, the individual probiotic species that demonstrated the greatest effect sizes were $B$. licheniformis (one study, $\mathrm{RR}=0.39$ ), $B$. longum (four studies, $\mathrm{RR}=0.46$ ) and $B$. subtilis (one study, $\mathrm{RR}=0.35)$. Although demonstrating a more moderate effect size, L. acidophilus (18 studies, $\mathrm{RR}=0.66)$, L. casei $(11$ studies, $\mathrm{RR}=0.59$ ) and $S$. boulardii (nine studies, $\mathrm{RR}=0.63$ ) were used in many more studies. Overall, the lactobacillus genus showed a good effect with a small CI. The individual species L. acidophilus was used in the greatest number of studies, demonstrating a moderate effect with a relatively small CI. Moderate effect sizes were noted with other species and strains, which may be worth looking into more specifically in future trials. L. helveticus, L. plantarum, L. reuteri, B. bifidum, S. thermophilus and C. butyricum did not show evidence of effectiveness in reducing incidence of AAD.

We found only one study ${ }^{34}$ comparing two strains of the same probiotic species, L. casei DN-114001, (Actimel) and L. casei Shirota (Yakult). In this study L. casei DN-114001 was significantly more effective for preventing AAD than L. casei Shirota. However, we were unable to include these data in our review as it was not randomised. Future RCTs should focus on direct comparisons of single or combined probiotic species and strains.

The most commonly identified indication for antibiotics was treatment of $H$. pylori. The reduction in diarrhoeal side effects by $45 \%$, through the use of adjunct probiotics, may be a significant finding in improving quality of life for these patients.

\section{Limitations}

A limitation of this study is that the only outcome measured was incidence of diarrhoea. This review's utility in clinical practice may have been improved by also analysing duration of $\mathrm{AAD}$, diarrhoea severity, need for hospitalisation due to diarrhoea and quality of life measures. Additionally, it may have been informative to correlate outcomes with the duration of probiotic course or the date of probiotic initiation in relation to antibiotics.

Subgroup analysis by antibiotic would have been informative but was not possible as many of the included studies did not state the antibiotic name, class, route of administration, dose or course length that participants were administered. Future studies could focus on this.

This study was somewhat limited in scope as we only included studies published in English. Additionally, the initial search was a title search as opposed to keyword search, which may explain the lower number of studies initially identified, compared with the recent Cochrane review. $^{21}$

\section{Agreements and disagreements with other studies}

This study is concordant with findings from the aforementioned Cochrane systematic review. ${ }^{21}$ Goldenberg found that probiotics led to a significant reduction in incidence of AAD from $18 \%$ to $12 \%$ of participants ( $R R=0.58$, 95\% CI 0.48 to 0.70$)$. The present review included 18 additional studies (4487 additional participants). This 
increase in total population increases the power of our review to detect smaller clinically relevant differences between groups in incidence of AAD.

Our subgroup analyses found similarly to one previous meta-analysis ${ }^{37}$ that the Lactobacillus and Saccharomyces genera reduced incidence of AAD. A more recent metaanalysis $^{38}$ found, also concordantly, that many Lactobacillus and Bifidobacteria species and S. boulardii were effective. Previous meta-analyses have not reported on dose-response.

Our subgroup analyses were also in agreement with The American Gastroenterological Association Clinical Practice Guidelines on the Role of Probiotics in the Management of Gastrointestinal Disorders ${ }^{39}$ which suggest the use of $S$. boulardii; or the two-strain combination of $L$. acidophilus CL1285 and L. casei LBC80R among other probiotic species for prevention of AAD.

Contrary to the findings of our review, one metaanalysis ${ }^{40}$ reported that probiotics may not be effective in reducing the incidence of AAD. However, only 13 studies were analysed, including adults over 65 only. This suggests a need for looking separately at the effectiveness of probiotics in populations of younger and older adults.

\section{CONCLUSIONS}

This review found evidence supporting a moderate protective effect for probiotics in preventing AAD. In absolute terms, the NNT, to prevent one case of AAD would be 20 patients. These results should be applied with caution in clinical scenarios with inherent lower baseline risk of $\mathrm{AAD}$. In studies that compared dosage of the same probiotic, higher doses were found to be significantly more effective, suggesting a recommended dose of greater than 10 billion cfu per day. Although the probiotic species that demonstrated the greatest effect were $B$. licheniformis, $B$. longum and $B$. subtilis, each was studied in only a handful of trials. The species L. acidophilus, L. casei and S. boulardii, still demonstrating moderate effect sizes in preventing $\mathrm{AAD}$, were used in many more trials. A good effect size was found supporting the use of probiotics, given concurrently with antibiotics for $H$. pylori eradication therapy.

This review has demonstrated overall effectiveness of probiotics for the prevention of AAD, including a doseresponse and some species-specific effectiveness of probiotics. Further high-quality trials are needed, focusing on direct comparison of doses, comparison of individual species and combinations of species. Future studies should record not only incidence of diarrhoea, but also duration, severity, quality of life measures and length of stay in hospital so that an assessment of the cost-benefit of probiotic therapy can be made. Future trials should ensure there is adequate blinding and reporting of adverse events.

Twitter Charlotte Hespe @runningdoc14 and Kate Levett @LevettKate

Acknowledgements We would like to thank Morgann Quilty, librarian at the School of Medicine, University of Notre Dame Australia, Sydney Campus, for her assistance with initial protocol development, A/Prof Sally Lord for her contribution and advice on the statistical analyses conducted in this review and Stephen Goodman for his assistance with tables and graphics. Additionally, we would like to thank Dr Gita Pawar and Dr Basant Pawar as well as the General Surgical team at Alice Springs Hospital for their invaluable feedback and review of abstracts and conference presentations.

Contributors Study concept and design: CG, CH, KL. Acquisition of data: CG, GK, $\mathrm{KL}$. Analysis and interpretation of data: CG, GK, KL. Drafting of the manuscript: CG, $\mathrm{KL}$. Critical revision of the manuscript for important intellectual content: CG, GK, EG, KL. Statistical analysis: CG, EG, KL. Study supervision: KL.

Funding The authors have not declared a specific grant for this research from any funding agency in the public, commercial or not-for-profit sectors.

Competing interests None declared.

Patient consent for publication Not required.

Ethics approval This systematic review and meta-analysis was based on published data. As researchers did not access any information that could lead to the identification of an individual patient, no concerning ethical issue was raised in this research. Therefore, obtaining ethical approval and consent of participants was waived.

Provenance and peer review Not commissioned; externally peer reviewed.

Data availability statement Raw data used and analysed during the current study are available from the corresponding author on reasonable request.

Supplemental material This content has been supplied by the author(s). It has not been vetted by BMJ Publishing Group Limited (BMJ) and may not have been peer-reviewed. Any opinions or recommendations discussed are solely those of the author(s) and are not endorsed by BMJ. BMJ disclaims all liability and responsibility arising from any reliance placed on the content. Where the content includes any translated material, BMJ does not warrant the accuracy and reliability of the translations (including but not limited to local regulations, clinical guidelines, terminology, drug names and drug dosages), and is not responsible for any error and/or omissions arising from translation and adaptation or otherwise.

Open access This is an open access article distributed in accordance with the Creative Commons Attribution Non Commercial (CC BY-NC 4.0) license, which permits others to distribute, remix, adapt, build upon this work non-commercially, and license their derivative works on different terms, provided the original work is properly cited, appropriate credit is given, any changes made indicated, and the use is non-commercial. See: http://creativecommons.org/licenses/by-nc/4.0/.

\section{ORCID iDs}

Clare Goodman http://orcid.org/0000-0002-5393-5665

Charlotte Hespe http://orcid.org/0000-0002-4582-7728

Kate Levett http://orcid.org/0000-0003-3784-4648

\section{REFERENCES}

1 Francino MP. Antibiotics and the human gut microbiome: Dysbioses and accumulation of resistances. Front Microbiol 2016;6:1543.

2 Young VB, Schmidt TM. Antibiotic-Associated diarrhea accompanied by large-scale alterations in the composition of the fecal microbiota. J Clin Microbiol 2004;42:1203-6.

3 Elseviers MM, Van Camp Y, Nayaert S, et al. Prevalence and management of antibiotic associated diarrhea in general hospitals. BMC Infect Dis 2015;15:129.

4 Bishara J, Peled N, Pitlik S, et al. Mortality of patients with antibioticassociated diarrhoea: the impact of Clostridium difficile. J Hosp Infect 2008;68:308-14.

5 Kamdeu Fansi AA, Guertin JR, LeLorier J. Savings from the use of a probiotic formula in the prophylaxis of antibiotic-associated diarrhea. J Med Econ 2012;15:53-60.

6 Lenoir-Wijnkoop I, Nuijten MJC, Craig J. Nutrition economic evaluation of a probiotic in the prevention of antibiotic-associated diarrhea. front Pharmacol 2014;5.

7 McFarland LV. Antibiotic-Associated diarrhea: epidemiology, trends and treatment. Future Microbiol 2008;3:563-78.

8 Hill C, Guarner F, Reid G, et al. Expert consensus document. The International scientific association for probiotics and prebiotics consensus statement on the scope and appropriate use of the term probiotic. Nat Rev Gastroenterol Hepatol 2014;11:506-14.

9 Sazawal S, Hiremath G, Dhingra U, et al. Efficacy of probiotics in prevention of acute diarrhoea: a meta-analysis of masked, 
randomised, placebo-controlled trials. Lancet Infect Dis 2006;6:374-82.

10 Naaber P, Mikelsaar M. Interactions between lactobacilli and antibiotic-associated diarrhea. Adv Appl Microbiol;54:231-60.

11 Elmer GW, McFarland LV. Suppression by Saccharomyces boulardii of toxigenic Clostridium difficile overgrowth after vancomycin treatment in hamsters. Antimicrob Agents Chemother 1987;31:129-31.

12 Pothoulakis C, Kelly CP, Joshi MA, et al. Saccharomyces boulardii inhibits Clostridium difficile toxin a binding and enterotoxicity in rat ileum. Gastroenterology 1993;104:1108-15.

13 Castagliuolo I, Riegler MF, Valenick L, et al. Saccharomyces boulardi protease inhibits the effects of Clostridium difficile toxins $A$ and $B$ in human colonic mucosa. Infect Immun 1999;67:302-7.

14 Link-Amster H, Rochat F, Saudan KY, et al. Modulation of a specific humoral immune response and changes in intestinal flora mediated through fermented milk intake. FEMS Immunol Med Microbio 1994;10:55-63.

15 Qamar A, Aboudola S, Warny M, et al. Saccharomyces boulardii stimulates intestinal immunoglobulin $A$ immune response to Clostridium difficile toxin A in mice. Infect Immun 2001;69:2762-5.

16 Yasui $\mathrm{H}$, Shida K, Matsuzaki T, et al. Immunomodulatory function of lactic acid bacteria. Antonie Van Leeuwenhoek 1999;76:383-9.

17 Gill HS, Rutherfurd KJ, Cross ML. Dietary probiotic supplementation enhances natural killer cell activity in the elderly: an investigation of age-related immunological changes. J Clin Immunol 2001;21:264-71.

18 Wilcox MH, Cunniffe JG, Trundle C, et al. Financial burden of hospital-acquired Clostridium difficile infection. J Hosp Infect 1996;34:23-30

19 Walk ST, Young VB. Emerging insights into antibiotic-associated diarrhea and Clostridium difficile infection through the lens of microbial ecology. Interdiscip Perspect Infect Dis 2008;2008:125081.

20 Independent Hospital Pricing Authority. National Hospital cost data collection report. 21, 2019. Available: https://www.ihpa.gov.au/sites/ default/files/publications/national_hospital_cost_data_collection_ australian public hospitals cost report round 21_2016-17.pdf

21 Goldenberg JZ, Yap C, Lytvyn L, et al. Probiotics for the prevention of Clostridium difficile-associated diarrhea in adults and children. Cochrane Database Syst Rev 2017;382.

22 Hurley BW, Nguyen CC. The spectrum of pseudomembranous enterocolitis and antibiotic-associated diarrhea. Arch Intern Med 2002;162:2177.

23 Horosheva T, Sorokulova I, Vodyanoy V. Efficacy of Bacillus probiotics in prevention of antibiotic-associated diarrhoea: a randomized, double-blind, placebo-controlled clinical trial. JMM Case Reports;1:1-6.

24 Moher D, Liberati A, Tetzlaff J. Preferred Reporting Items for Systematic Reviews and Meta-Analyses: The PRISMA Statement (Reprinted from Annals of Internal Medicine. PLoS Med;6:1-6.

25 Higgins J, Altman D. Chapter 8: Assessing risk of bias in included studies Table 8.5 a. In: Higgins JPT, Green S, eds. Cochrane Handbook for systematic reviews of interventions version 5.0.1. London: The Cochrane Collaboration, 2008: 1-50.

26 Guyatt $\mathrm{GH}$, Oxman AD, Vist GE, et al. GRADE: An emerging consensus on rating quality of evidence and strength of recommendations. BMJ 2008;336:924-6.

27 Velasco M, Requena T, Delgado-Iribarren A, et al. Probiotic yogurt for the prevention of antibiotic-associated diarrhea in adults: a randomized double-blind placebo-controlled trial. J Clin Gastroenterol 2019;53:717-23.

28 Gao XW, Mubasher M, Fang CY, et al. Dose-Response efficacy of a proprietary probiotic formula of Lactobacillus acidophilus CL1285 and Lactobacillus casei LBC80R for antibiotic-associated diarrhea and Clostridium difficile -associated diarrhea prophylaxis in adult patients. Am J Gastroenterol 2010;105:1636-41.

29 Imase K, Takahashi M, Tanaka A, et al. Efficacy of Clostridium butyricum preparation concomitantly with Helicobacter pylori eradication therapy in relation to changes in the intestinal microbiota. Microbiol Immunol 2008;52:156-61.

30 Ouwehand AC, DongLian C, Weijian X, et al. Probiotics reduce symptoms of antibiotic use in a hospital setting: a randomized dose response study. Vaccine 2AD;32:458-63.

31 Wu J, Gan T, Zhang Y, et al. The prophylactic effects of BIFICO on the antibiotic-induced gut dysbiosis and gut microbiota. Gut Pathog 2020;12:1-11.

32 Higgins J, Thomas J, Chandler J. Cochrane Handbook for systematic reviews of interventions. Hoboken: John Wiley \& Sons, 2019.

33 de Vrese M, Kristen H, Rautenberg P, et al. Probiotic lactobacill and bifidobacteria in a fermented milk product with added fruit preparation reduce antibiotic associated diarrhea and Helicobacter pylori activity. J Dairy Res 2011;78:396-403.
34 Dietrich CG, Kottmann T, Alavi M. Commercially available probiotic drinks containing Lactobacillus casei DN-114001 reduce antibioticassociated diarrhea. World J Gastroenterol 2014;20:15837-44.

35 Can M, Beșirbellioglu BA, Avci IY, et al. Prophylactic Saccharomyces boulardii in the prevention of antibiotic-associated diarrhea: a prospective study. Med Sci Monit 2006;12:PI19-22.

36 Price DD, Finniss DG, Benedetti F. A comprehensive review of the placebo effect: recent advances and current thought. Annu Rev Psychol 2008;59:565-90.

37 Hempel S, Newberry SJ, Maher AR, et al. Probiotics for the prevention and treatment of antibiotic-associated diarrhea: a systematic review and meta-analysis. JAMA 2012;307:1959-69.

38 Jafarnejad S, Shab-Bidar S, Speakman JR, et al. Probiotics reduce the risk of antibiotic-associated diarrhea in adults (18-64 years) but not the elderly (>65 years): a meta-analysis. Nutr Clin Pract 2016;31:502-13

39 Su GL, Ko CW, Bercik P, et al. AGA clinical practice guidelines on the role of probiotics in the management of gastrointestinal disorders. Gastroenterology 2020;159:697-705.

40 Xie C, Li J, Wang K, et al. Probiotics for the prevention of antibioticassociated diarrhoea in older patients: a systematic review. Travel Med Infect Dis 2015;13:128-34.

41 Allen SJ, Wareham K, Wang D, et al. Lactobacilli and bifidobacteria in the prevention of antibiotic-associated diarrhoea and Clostridium difficile diarrhoea in older inpatients (PLACIDE): a randomised, double-blind, placebo-controlled, multicentre trial. Lancet 20AD;382:1249-57.

42 Beausoleil M, Fortier N, Guénette S, et al. Effect of a fermented milk combining Lactobacillus acidophilus Cl1285 and Lactobacillus case in the prevention of antibiotic-associated diarrhea: a randomized, double-blind, placebo-controlled trial. Can J Gastroenterol 2007;21:732-6.

43 Beniwal RS, Arena VC, Thomas L, et al. A randomized trial of yogurt for prevention of antibiotic-associated diarrhea. Dig Dis Sci 2003;48:2077-82.

44 Bravo MV, Bunout D, Leiva L, et al. Efecto del probiótico Saccharomyces boulardii en La prevención de la diarrea asociada Con antibióticos en adultos ambulatorios en tratamiento Con amoxicilina. Rev Med Chil 2008;136:981-8.

45 Chatterjee S, Kar P, Das T, et al. Randomised placebo-controlled double blind multicentric trial on efficacy and safety of Lactobacillus acidophilus LA-5 and Bifidobacterium BB-12 for prevention of antibiotic-associated diarrhoea. J Assoc Physicians India 2013;61:708-12.

46 Cimperman L, Bayless G, Best K, et al. A randomized, double-blind, placebo-controlled pilot study of Lactobacillus reuteri ATCC 55730 for the prevention of antibiotic-associated diarrhea in hospitalized adults. J Clin Gastroenterol 2011;45:785-9.

47 Cindoruk M, Erkan G, Karakan T, et al. Efficacy and safety of Saccharomyces boulardii in the 14-day triple anti-Helicobacter pylori therapy: a prospective randomized placebo-controlled double-blind study. Helicobacter 2007;12:309-16.

48 Duman DG, Bor S, Ozütemiz O, et al. Efficacy and safety of Saccharomyces boulardii in prevention of antibiotic-associated diarrhoea due to Helicobacterpylori eradication. Eur J Gastroenterol Hepatol 2005;17:1357-61.

49 Ehrhardt S, Guo N, Hinz R, et al. Saccharomyces boulardii to prevent antibiotic-associated diarrhea: A randomized, double-masked, placebo-controlled trial. Open Forum Infect Dis 2016;3:1-7.

50 Evans M, Salewski RP, Christman MC, et al. Effectiveness of Lactobacillus helveticus and Lactobacillus rhamnosus for the management of antibiotic-associated diarrhoea in healthy adults: a randomised, double-blind, placebo-controlled trial. Br J Nutr 2016;116:94-103.

51 Gotz V, Romankiewicz JA, Moss J, et al. Prophylaxis against ampicillin-associated diarrhea with a Lactobacillus preparation. Am J Hosp Pharm 1979;36:754-7

52 Helps A, Bell E, Mactier R. Prospective randomized double-blind study of efficacy of probiotic milk drink in reducing the incidence of antibiotic-associated diarrhoea and Clostridium difficile diarrhoea. Int J Probiotics Prebiotics 2015;11:145-52.

53 Hickson M, D'Souza AL, Muthu N, et al. Use of probiotic Lactobacillus preparation to prevent diarrhoea associated with antibiotics: randomised double blind placebo controlled trial. BMJ 2007;335:80

54 lamharit J, Harnsomburana P. Prophylactic use of probiotic (Infloran (B) to prevent antibiotic associated diarrhea in medical ward patients at Rajavithi Hospital. Thai J Gastroenterol 2010;11:155-60.

55 Khanal A, Mishra A, Shrestha D. Efficacy of a mixture of probiotic containing Saccharomyces boulardii and Lactobacillus in preventing antibiotic associated diarrhea in patients taking 
triple therapy for $\mathrm{H}$ pylori eradication. Post-Graduate Med $\mathrm{J}$ 2015;15:28-32.

56 Koning CJM, Jonkers DMAE, Stobberingh EE, et al. The effect of a multispecies probiotic on the intestinal microbiota and bowel movements in healthy volunteers taking the antibiotic amoxycillin. Am J Gastroenterol 2008;103:178-89.

57 Lewis SJ, Potts LF, Barry RE. The lack of therapeutic effect of Saccharomyces boulardii in the prevention of antibiotic-related diarrhoea in elderly patients. J Infect 1998;36:171-4.

58 Lönnermark E, Friman V, Lappas G, et al. Intake of Lactobacillus plantarum reduces certain gastrointestinal symptoms during treatment with antibiotics. J Clin Gastroenterol 2010;44:106-12.

59 McFarland LV, Surawicz CM, Greenberg RN, et al. Prevention of beta-lactam-associated diarrhea by Saccharomyces boulardii compared with placebo. Am J Gastroenterol 1995;90:439-48.

60 Pirker A, Stockenhuber A, Remely M, et al. Effects of antibiotic therapy on the gastrointestinal microbiota and the influence of Lactobacillus casei. Food Agric Immunol 2013;24:315-30.

61 Plomer M, III Perez M, Greifenberg DM. Effect of Bacillus clausii capsules in reducing adverse effects associated with Helicobacter pylori eradication therapy: a randomized, double-blind, controlled trial. Infectious Diseases and Therapy 2020;9:867-78.

62 Plummer S, Weaver MA, Harris JC, et al. Clostridium difficile pilot study: effects of probiotic supplementation on the incidence of $\mathrm{C}$. difficile diarrhoea. Int Microbiol 2004;7:59-62.

63 Pozzoni P, Riva A, Bellatorre AG, et al. Saccharomyces boulardii for the prevention of antibiotic-associated diarrhea in adult hospitalized patients: a single-center, randomized, double-blind, placebocontrolled trial. Am J Gastroenterol 2012;107:922-31.

64 Rajkumar C, Wilks M, Islam J, et al. Do probiotics prevent antibioticassociated diarrhoea? results of a multicentre randomized placebocontrolled trial. J Hosp Infect 2020;105:280-8.
65 Safdar N, Barigala R, Said A, et al. Feasibility and tolerability of probiotics for prevention of antibiotic-associated diarrhoea in hospitalized US military veterans. J Clin Pharm Ther 2008;33:663-8.

66 Sampalis J, Psaradellis E, Rampakakis E. Efficacy of BIO K+ CL1285 in the reduction of antibiotic-associated diarrhea - a placebo controlled double-blind randomized, multi-center study. Arch Med Sci 2010;6:56-64.

67 Selinger CP, Bell A, Cairns A, et al. Probiotic VSL\#3 prevents antibiotic-associated diarrhoea in a double-blind, randomized, placebo-controlled clinical trial. J Hosp Infect 2013;84:159-65.

68 Shimbo I, Yamaguchi T, Odaka T, et al. Effect of Clostridium butyricum on fecal flora in Helicobacter pylori eradication therapy. World J Gastroenterol 2005;11:7520-4.

69 Song HJ, Kim J-Y, Jung S-A, et al. Effect of probiotic Lactobacillus

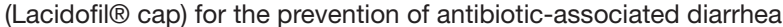
a prospective, randomized, double-blind, multicenter study. J Korean Med Sci 2010;25:1784-91.

70 Surawicz CM, Elmer GW, Speelman P, et al. Prevention of antibioticassociated diarrhea by Saccharomyces boulardii: a prospective study. Gastroenterology 1989;96:981-8.

71 Thomas MR, Litin SC, Osmon DR, et al. Lack of effect of Lactobacillus GG on antibiotic-associated diarrhea: a randomized, placebo-controlled trial. Mayo Clin Proc 2001;76:883-9.

72 Wenus C, Goll R, Loken EB, et al. Prevention of antibiotic-associated diarrhoea by a fermented probiotic milk drink. Eur J Clin Nutr 2008;62:299-301.

73 Wong S, Jamous A, O'Driscoll J, et al. A Lactobacillus casei Shirota probiotic drink reduces antibiotic-associated diarrhoea in patients with spinal cord injuries: a randomised controlled trial. Br J Nutr 2014;111:672-8.

74 Wright K, Wright $\mathrm{H}$, Murray M. Probiotic treatment for the prevention of antibiotic-associated diarrhoea in geriatric patients: a multicentre randomised controlled pilot study. Australas J Ageing 2015;34:38-42. 